\title{
SIGN-R1, a C-type lectin, enhances apoptotic cell clearance through the complement deposition pathway by interacting with $\mathrm{C} 1 \mathrm{q}$ in the spleen
}

\author{
MG Prabagar, ${ }^{1,11}$, Y Do ${ }^{2,11}$, S Ryu ${ }^{3,11}$, J-Y Park ${ }^{1}$, H-J Choi ${ }^{1}$, W-S Choi ${ }^{4}$, TJ Yun ${ }^{5}$, J Moon ${ }^{6}$, I-S Choi ${ }^{7}, K_{K}{ }^{8}$, K Ko \\ C Young Shin ${ }^{10}$, C Cheong ${ }^{6}$ and Y-S Kang ${ }^{*, 1}$
}

Complements, such as $\mathrm{C} 1 \mathrm{q}$ and $\mathrm{C} 3$, and macrophages in the splenic marginal zone (MZMs) play pivotal roles in the efficient uptake and processing of circulating apoptotic cells. SIGN-R1, a C-type lectin that is highly expressed in a subpopulation of MZMs, regulates the complement fixation pathway by interacting with C1q, to fight blood-borne Streptococcus pneumoniae. Therefore, we examined whether the SIGN-R1-mediated classical complement pathway plays a role in apoptotic cell clearance and immune tolerance. SIGN-R1 first-bound apoptotic cells and this binding was significantly enhanced in the presence of C1q. SIGN-R1-C1q complex then immediately mediated $\mathrm{C} 3$ deposition on circulating apoptotic cells in the MZ, leading to the efficient clearance of them. SIGN-R1-mediated C3 deposition was completely abolished in the spleen of SIGN-R1 knockout (KO) mice. Given that SIGN-R1 is not expressed in the liver, we were struck by the finding that C3-deposited apoptotic cells were still found in the liver of wild-type mice, and dramatically reduced in the SIGN-R1 KO liver. In particular, SIGN-R1 deficiency caused delayed clearance of apoptotic cells and aberrant secretion of cytokines, such as TNF- $\alpha$, IL- 6 , and TGF- $\beta$ in the spleen as well as in the liver. In addition, anti-double- and single-stranded DNA antibody level was significantly increased in SIGN-R1-depleted mice compared with control mice. These findings suggest a novel mechanism of apoptotic cell clearance which is initiated by SIGN-R1 in the MZ and identify an integrated role of SIGN-R1 in the systemic clearance of apoptotic cells, linking the recognition of apoptotic cells, the opsonization of complements, and the induction of immune tolerance.

Cell Death and Differentiation (2013) 20, 535-545; doi:10.1038/cdd.2012.160; published online 14 December 2012

Apoptosis, or programmed cell death, is a highly regulated physiological process that involves numerous receptors and bridging molecules. ${ }^{1}$ In higher organisms, billions of apoptotic cells that are generated in physiological homeostasis are rapidly and efficiently removed by professional phagocytes in an immunologically silent way. ${ }^{2}$ As professional phagocytes, macrophages are the primary cells in charge of clearing apoptotic cells. ${ }^{3}$ The recognition and clearance of apoptotic cells by these macrophages activates tolerogenic pathways in an effort to prevent an immune response against selfantigens. ${ }^{4}$ The impaired clearance of apoptotic cells may influence the resolution of inflammation or trigger autoimmune disorders ${ }^{4}$ such as rheumatoid arthritis, systemic lupus erythematosus, glomerulonephritis, and atherosclerosis. ${ }^{5-8}$
Apoptotic cells that enter the splenic artery from the circulation accumulate primarily in the splenic marginal zone $(\mathrm{MZ}){ }^{9,10}$ The $\mathrm{MZ}$ is an anatomical region that surrounds the white pulp nodules and separates these lymphocyte-rich regions from the vascular and macrophagerich red pulp. ${ }^{11}$ The $\mathrm{MZ}$ macrophages (MZMs) are a small subset of specialized splenic macrophages that express an array of receptors, such as the macrophage receptor with collagenous structure (MARCO), scavenger receptor A (SR-A), and specific intercellular adhesion molecule-3-grabbing nonintegrin-related 1 (SIGN-R1). ${ }^{12,13} \mathrm{MZMs}$ regulate not only the efficient clearance of circulating apoptotic cells, but also the selective engulfment of dying cells by $\mathrm{CD} 8 \alpha^{+}$ DCs. ${ }^{14}$ This mechanism is important in tolerance to

\footnotetext{
${ }^{1}$ Department of Biomedical Science and Technology, SMART Institute of Advanced Biomedical Science, Institute of Functional Genomics, Konkuk University, 1 Hwayang-dong, Gwangjin-gu, Seoul 143-701, Republic of Korea; ${ }^{2}$ School of Nano-Bioscience and Chemical Engineering, Ulsan National Institute of Science and Technology, \#100 Banyeon-ri, Eonyang-eup, Ulju-gun, Ulsan 689-805, Republic of Korea.; ${ }^{3}$ Department of Cardiothoracic Surgery, Weill Cornell Medical College of Cornell University, NY 10065, USA; ${ }^{4}$ Laboratory Animal Center, Daegu-Gyeongbuk Medical Innovation Foundation (DGMIF), 2387 Dalgubeol-daero, Suseong-gu, Daegu 557-10, Republic of Korea; ${ }^{5}$ Institut de Recherches Cliniques de Montréal (IRCM), 110 avenue des Pins Ouest, Montréal (Quebec) Canada; ${ }^{6}$ Department of Microbiology and Immunology, University of Montreal, Montreal (Quebec), Canada; ${ }^{7}$ Department of Infectious Diseases, College of Veterinary Medicine, Konkuk University, 1 Hwayang-dong, Gwangjin-gu, Seoul 143-701, Republic of Korea; ${ }^{8}$ Department of Medicine, Medical Research Institute, College of Medicine, Chung-Ang University, 156-756 Seoul, Korea; ${ }^{9}$ Department of Stem Cell Biology, School of Medicine, SMART Institute of Advanced Biomedical Science, Konkuk University, 1 Hwayang-dong, Gwangjin-gu, Seoul 143-701, Republic of Korea and ${ }^{10}$ Department of Pharmacology, School of Medicine, SMART Institute of Advanced Biomedical Science, Konkuk University, 1 Hwayang-dong, Gwangjin-gu, Seoul 143-701, Republic of Korea

${ }^{*}$ Corresponding author: Y-S Kang, Department of Biomedical Science and Technology, SMART Institute of Advanced Biomedical Science, Institute of Functional Genomics, Konkuk University, 1 Hwayang-dong, Gwangjin-gu, Seoul 143-701, Republic of Korea. Tel: + 822 2049 6023; Fax: +82 24469001.

E-mail: kangyo67@konkuk.ac.kr

${ }^{11}$ These authors contributed equally to this work.

Keywords: SIGN-R1; splenic marginal zone macrophages; complements; apoptotic cells; autoimmune disease

Abbreviations: MZ, splenic marginal zone; MZMs, MZ macrophages; CFSE, carboxyfluorescein succinimidyl ester; CVF, cobra venom factor; KO, knockout; TKO, transient knockout; dsDNA, double-stranded DNA; ssDNA, single-stranded DNA

Received 06.6.12; revised 02.11.12; accepted 12.11.12; Edited by S Nagata; published online 14.12 .12
} 
cell-associated antigens, providing the maintenance of selftolerance. . $10,15^{2}$

Complement C3 contributes to the opsonization of apoptotic cells, ${ }^{16,17}$ and facilitates their opsonin-dependent phagocytosis, playing a pivotal role in the efficient clearance of apoptotic cells. ${ }^{18,19}$ Also, complement receptor-mediated phagocytosis optimize the uptake of apoptotic cells and instruct DCs to induce immune tolerance. ${ }^{15}$ In addition, C1q and mannosebinding lectin (MBL) directly bind to apoptotic cells, ${ }^{20-24}$ facilitating the phagocytosis of apoptotic cells by macrophages. $^{22,24}$ Because C1q-deficient mice show impaired clearance of apoptotic cells ${ }^{7}$ and both C1q-deficient mice and humans are strongly susceptible to autoimmunity, C1q may play an important role in the apoptotic cell clearance. ${ }^{25}$

SIGN-R1, which is the murine homolog of human dendritic cell-specific intercellular adhesion molecule-3-grabbing nonintegrin (DC-SIGN, CD209), is a transmembrane C-type lectin that is highly expressed on a subpopulation of MZMs. ${ }^{13}$ SIGN$\mathrm{R} 1$ directly binds to $\mathrm{C} 1 \mathrm{q}$ and dominantly regulates the immunoglobulin-independent classical complement pathway for C3 deposition of blood-borne Streptococcus pneumoniae. $^{26}$ In SIGN-R1-deficient mice, C3 deposition is abolished and innate resistance against pneumococci is reduced. ${ }^{26,27}$ SIGN-R1 interacts specifically with 2,6 sialylated Fc fragments of immunoglobulins, resulting in the anti-inflammatory activity of intravenous immunoglobulin, which has been widely used to treat autoimmune diseases, including immune thrombocytopenia, rheumatoid arthritis, and systemic lupus erythematosus. $^{28,29}$

In the present study, we demonstrate that SIGN-R1 first binds to apoptotic cells and this binding is enhanced by interacting with C1q. And SIGN-R1-C1q complex immediately mediates C3 deposition on apoptotic cells, thus promoting their systemic clearance and maintaining immune tolerance in vivo.

\section{Results}

Direct interactions between SIGN-R1 and apoptotic cells in vitro. We examined whether SIGN-R1 can directly bind to apoptotic cells. Apoptotic Jurkat T cells or thymocytes were prepared with dexamethasone or $\gamma$-irradiation, and apoptosis induction was confirmed by Annexin- $V$ and propidium iodide (PI) double staining in fluorescence-activated cell sorting (FACS) analysis, showing no PI-single positive necrotic cells (Supplementary Figure 1). We incubated nonapoptotic and apoptotic Jurkat T cells with purified SIGN-R1 and performed FACS analysis with a monoclonal anti-SIGN-1 antibody (22D1). Contrary to nonapoptotic cells, SIGN-R1 preferentially bound to Annexin-V-positive apoptotic cells (Figure 1a). To further confirm SIGN-R1 binding to apoptotic cells, apoptotic thymocytes were treated with biotinylated recombinant SIGN-R1 and the binding of SIGN-R1 to apoptotic thymocytes was evident (Figure 1b, third row). The specificity of this binding was verified with irrelevant biotin-conjugated proteins, such as transferrin (Tfe) and endotoxin-free OVA (efOVA) (Figure 1b, first and second rows). When Alexa568conjugated purified SIGN-R1 or efOVA (red) were incubated with carboxyfluorescein succinimidyl ester (CFSE)-labeled nonapoptotic or apoptotic thymocytes (green), SIGN-R1 only bound to the surface of apoptotic cells (Figure 1c). To further confirm SIGN-R1 binding to apoptotic cells, we used whole cell lysate of DCEK_SIGN-R1 transfectant as a source of SIGN-R1 and also observed the specific binding of SIGN-R1 to apoptotic cells (Figure 1d).

The direct binding of apoptotic cells to SIGN-R1transfected cells. The binding of SIGN-R1 to apoptotic cells was examined by FACS analysis using DCEK or $\mathrm{CHO}$ transfectant cell lines. The binding of apoptotic thymocytes to parental DCEK_wild-type (WT) or DCEK transfectant expressing mouse DC-SIGN (mDC-SIGN) was not significant, even at $1: 20$ ratio of DCEKs-to-apoptotic cells (Figure $2 a$, first and second rows). However, the binding of apoptotic cells to DCEK_SIGN-R1 was evident and dependent on the dose of apoptotic thymocytes, becoming significant at a $1: 4$ ratio and the highest at a 1:20 ratio (Figure $2 a$, third row). The bound number of apoptotic cells in FACS results was presented for the respective cell lines (Figure $2 \mathrm{a}$, right graph). To confirm the binding of apoptotic cells to SIGN-R1, the same experiment was performed with $\mathrm{CHO}$ transfectant cell lines, and similar results were obtained, showing the specific binding affinity of apoptotic cells only on CHO_SIGN-R1 (Figure 2b, right graph).

The binding of apoptotic cells to SIGN-R1 was further confirmed at a 1:4 ratio of DCEKs-to-apoptotic cells by fluorescent microscopy. Although a few apoptotic cells were bound to DCEK_WT, the clustering of apoptotic cells (blue, arrow heads) was obvious on the cellular surface of DCEK_SIGN-R1 $(P<0.05) \quad$ (Figure 2c, right graph; Supplementary Figure 2), confirming the FACS results of Figures $2 \mathrm{a}$ and $\mathrm{b}$. Apoptotic cell binding was obvious only on DCEK_SIGN-R1, even at $4{ }^{\circ} \mathrm{C}$, directly indicating that SIGN$\mathrm{R} 1$ is a receptor for apoptotic cells (Figure $2 \mathrm{~d}$ ). To examine the binding efficiency of apoptotic cells to SIGN-R1, two-color FACS analysis was performed. Apoptotic cell binding to SIGN-R1 was evident even at 30 min in DCEK_SIGN-R1, and maintained for $2 \mathrm{~h}$ (Figure $2 \mathrm{e}$, bottom row), confirming the specificity of SIGN-R1 to apoptotic cells. Although some binding of apoptotic cells to DCEK_mDC-SIGN was seen at $30 \mathrm{~min}$, this binding was mostly absent at $2 \mathrm{~h}$, suggesting nonspecific binding or low-binding affinity of mDC-SIGN to apoptotic cells.

The initial recognition and uptake of apoptotic cells by SIGN-R1 ${ }^{+}$macrophages in the MZ. To verify the function of SIGN-R1 on apoptotic cell clearance in vivo, we examined the distribution of apoptotic cells around the MZ. Spleen sections were examined 30 min after an intravenous injection of CFSE-labeled Jurkat cells $\left(5 \times 10^{7}\right.$ cells/mouse) or TRITCconjugated latex beads $\left(1 \times 10^{10} / \mathrm{kg}\right)$. Contrary to the abundance of nonapoptotic Jurkat cells ${ }^{30,31}$ or TRITC-latex beads $^{13}$ in the red pulp (Figure $3 a$, left or Supplementary Figure $3 a$, left row), the majority of apoptotic Jurkat cells were primarily entrapped in the $M Z$, especially on SIGN-R1 ${ }^{+}$ macrophages (Figure $3 a$, right), showing the similar results with previous reports. ${ }^{9,10,32} \mathrm{Next}$, we confirmed the uptake of apoptotic thymocytes by SIGN-R1 ${ }^{+}$macrophages in vivo. Similar to Figure 3a, apoptotic thymocytes were clearly seen in SIGN-R1 ${ }^{+}$macrophages 30 min after the injection of them (Figure 3b, fourth column). Interestingly, apoptotic 
a
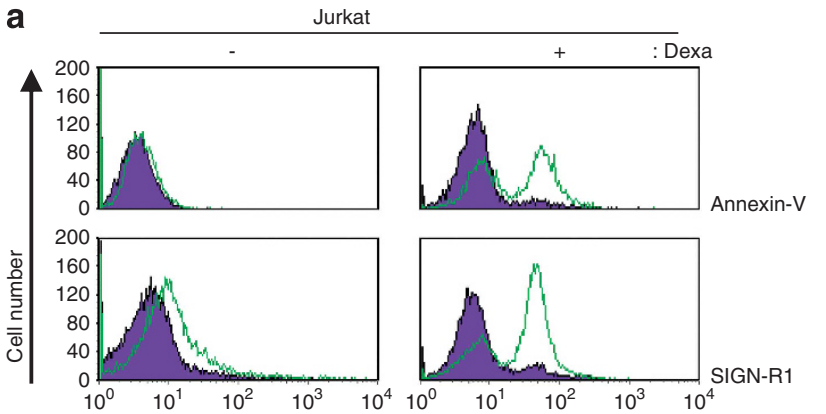

b

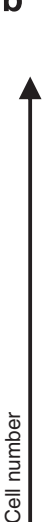

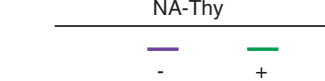
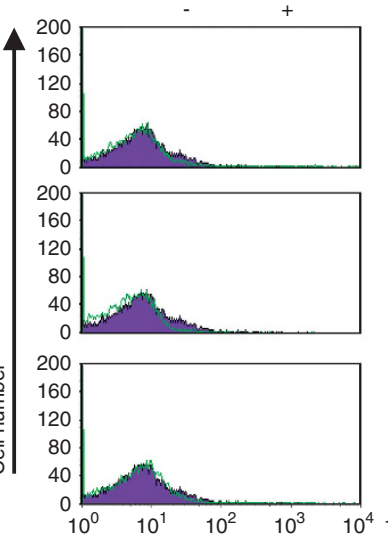
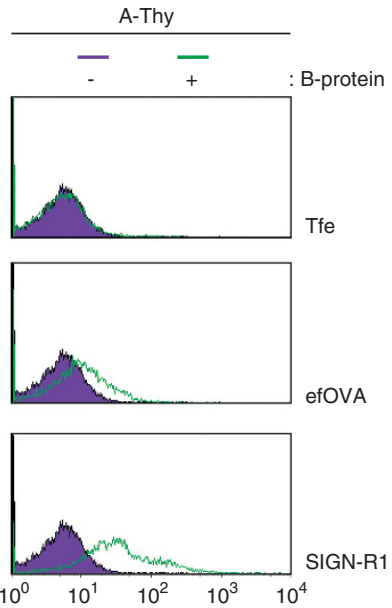

d
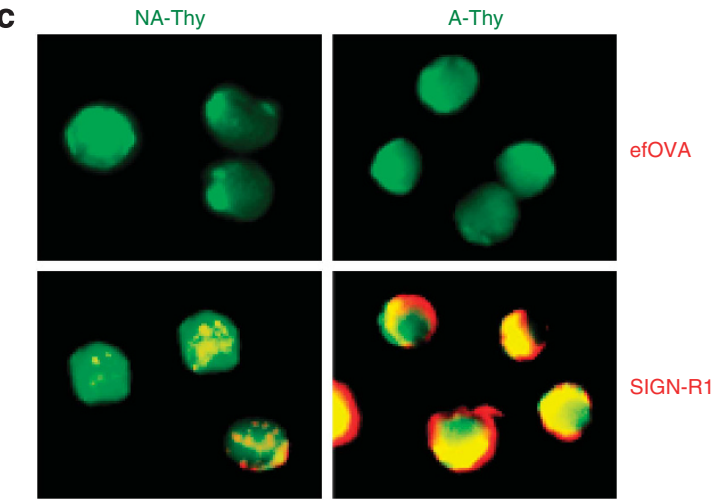

Whole cell lysate of DCEKs +
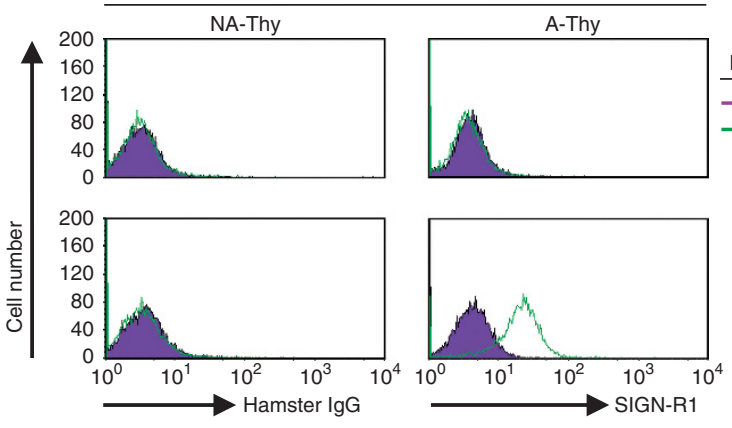

Figure 1 SIGN-R1 directly binds to apoptotic cells in vitro. (a) Jurkat T cells were treated with $3 \mu \mathrm{M}$ of dexamethasone (Dexa) for $24 \mathrm{~h}$, and apoptosis induction was confirmed with Annexin-V, followed by FACS analysis. Nonapoptotic and apoptotic Jurkat T cells were incubated with $2 \mu \mathrm{g}$ of purified recombinant SIGN-R1 for 30 min at $37^{\circ} \mathrm{C}$ and immunostained with a 22D1 anti-SIGN-R1 monoclonal antibody, which was followed by a FACS analysis. (b) Apoptotic thymocytes of C57BL/6 mice were prepared as in (a), and $1 \times 10^{6}$ nonapoptotic or apoptotic thymocytes were incubated with $2 \mu \mathrm{g}$ of biotinylated transferrin (Tfe), efOVA, or recombinant purified SIGN-R1 for 30 min at $37^{\circ} \mathrm{C}$ and immunostained with Alexa488-conjugated Streptavidin, which was followed by a FACS analysis. (c) As in (c), but thymocytes were incubated with $2 \mu \mathrm{g}$ of Alexa568conjugated efOVA or purified SIGN-R1 (red) and analyzed by fluorescent microscopy. (d) As in (b), but $1 \times 10^{6}$ nonapoptotic or apoptotic thymocytes (NA- or A-Thy, respectively) were incubated with $20 \mu \mathrm{g}$ of whole cell lysates from DCEK_WT, or_SIGN-R1 cells for $1 \mathrm{~h}$ at $37^{\circ} \mathrm{C}$ and immunostained with ananti-SIGN-R1 monoclonal antibody (Clone 22D1) or a nonreactive hamster lgG control

thymocytes were found in the $M Z$ as early as $10 \mathrm{~min}$ after their injection (Figure 3b, third column), whereas nonapoptotic thymocytes were not in the spleen at this time point (Figure 3b, first column), indicating that the SIGN$\mathrm{R} 1^{+}$macrophages rapidly took up apoptotic cells from the circulation.

To determine if SIGN-R1 ${ }^{+}$macrophages are critical for the uptake of circulating apoptotic cells in the MZ, we intravenously injected CFSE-labeled apoptotic thymocytes into SIGN-R1 transient knockout (TKO) mice, which specifically and transiently deplete surface SIGN-R1 molecule, but not SIGN-R1 \pm macrophages. ${ }^{33}$ The distribution of nonapoptotic thymocytes in TKO mice was similar in control mouse of Figure 3b (Figure 3c, left panel). However, apoptotic cells were significantly lower in both the $M Z$ and the red pulp at 30 min (Figure 3c, right panel), implying that SIGN-R1 is essential for the initial recognition of apoptotic cells. Next, we examined the clearance efficiency of apoptotic cells in isotype control and SIGN-R1 TKO mice for $1 \mathrm{~h}$. In control mice, apoptotic thymocytes were mostly absent at $1 \mathrm{~h}$, suggesting a rapid clearance of apoptotic cells from the spleen (Figure 3d, upper row and right graph). However, apoptotic cells still accumulated in the MZ after $1 \mathrm{~h}$ in SIGN-R1 TKO mice (Figure 3d, lower row and right graph). The same results were observed in the spleen of SIGN-R1 KO mice (Supplementary Figure 3b).

C1q enhances the specific binding of SIGN-R1 to apoptotic thymocytes. C1q binds to apoptotic cells $\mathrm{s}^{20,21}$ as well as SIGN-R1. ${ }^{26}$ Therefore, we examined whether $\mathrm{C} 1 \mathrm{q}$ is competitive or synergistic for SIGN-R1 binding to apoptotic cells. First, we confirmed the dose-dependent binding of $\mathrm{C} 1 \mathrm{q}$ to apoptotic cells (Figure 4a). Next, DCEK transfectants (red) and apoptotic thymocytes (green) were coincubated with or without purified $\mathrm{C} 1 \mathrm{q}$ at a $1: 1$ ratio of DCEKs-to-apoptotic cells in which the binding of apoptotic cells to DCEK_SIGN$\mathrm{R} 1$ was unfavorable (Figures $2 \mathrm{a}$ and $\mathrm{b}$ ) and the binding of apoptotic thymocytes to each DCEK transfectants was analyzed by two-color FACS analysis. The addition of $\mathrm{C} 1 \mathrm{q}$ significantly enhanced the binding of apoptotic cells only to 
a

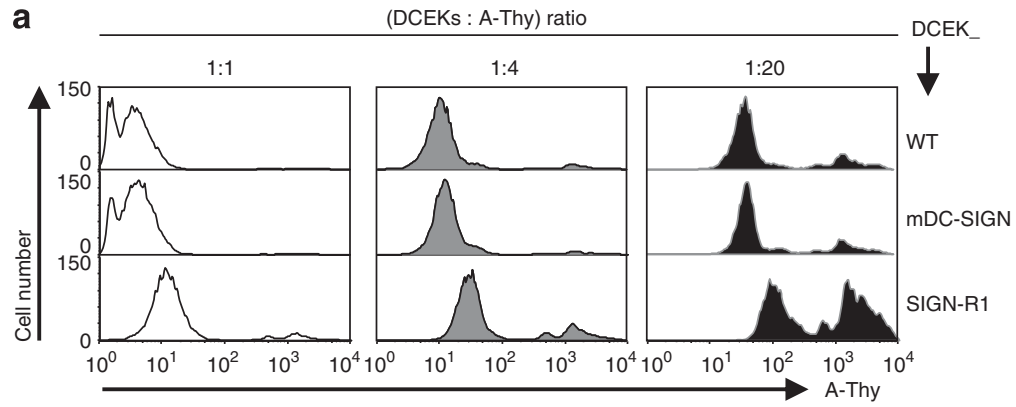

b
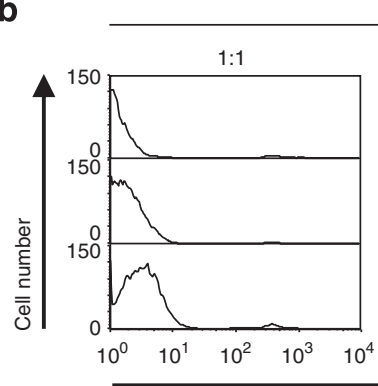

(CHOs : A-Thy) ratio
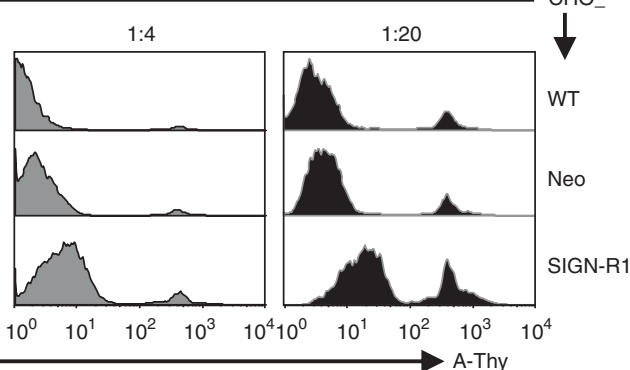

C

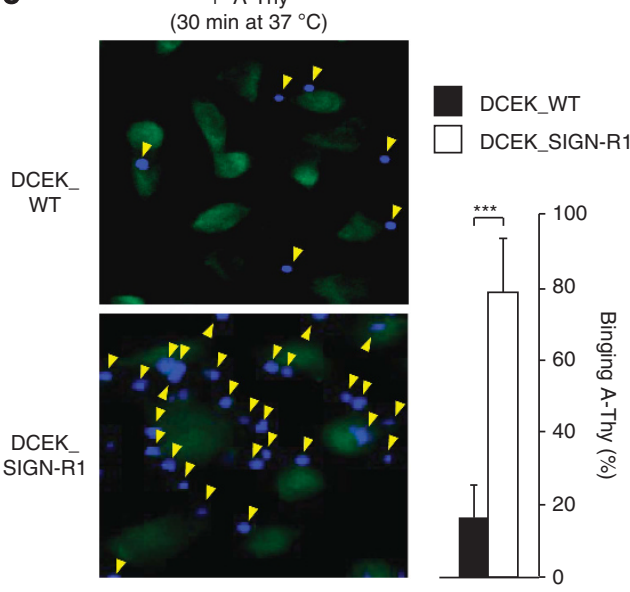

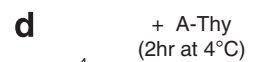

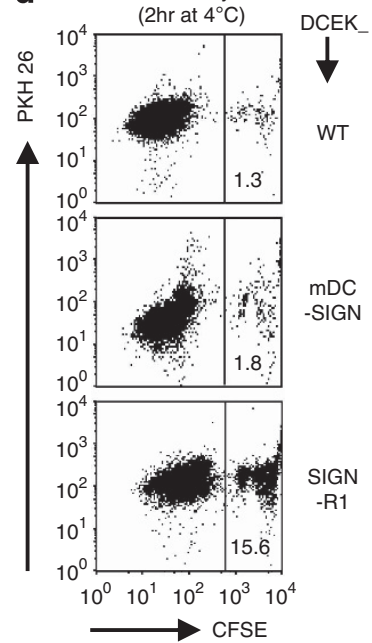

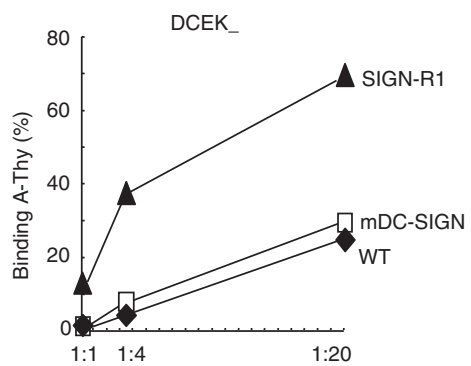

$\mathrm{CHO}_{-}$

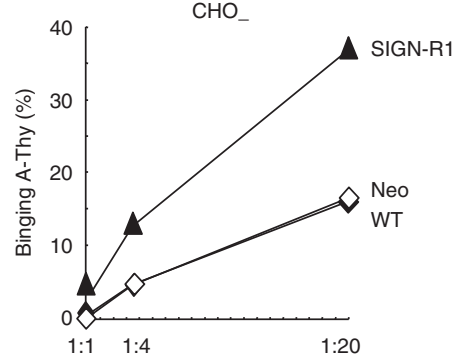

e
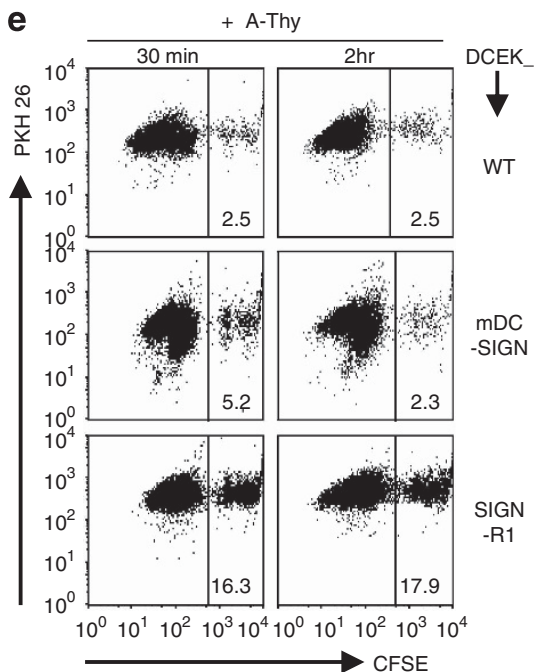

Figure 2 SIGN-R1-transfected cells directly bind to apoptotic cells in vitro. (a) Apoptotic thymocytes were prepared as in Figure 1. (b) DCEK transfectants $\left(1 \times 10^{6}\right)$ and CFSE-labeled apoptotic thymocytes were coincubated in the presence of $1 \%$ fresh normal mouse serum for 30 min at $37^{\circ} \mathrm{C}$ at the indicated ratios $(1: 1,1: 4$, or $1: 20)$, and apoptotic cell binding was assessed by a FACS analysis. The average values of apoptotic cell binding (\%) from three independent experiments were calculated (right). (b) As in (a), but apoptotic cell binding was assessed with the indicated CHO transfectants. (c) As in (a), but CFSE-labeled DCEK_WT or_SIGN-R1 transfectants (green) were coincubated with Hoechst 33258-labeled apoptotic thymocytes (blue) at a 1:4 ratio, and apoptotic cell binding was assessed by florescent microscopy. Arrows indicate apoptotic cells bound to DCEKs (left). Apoptotic cells bound to DCEKs were counted, and their average values from three independent experiments were calculated (right). (d) Apoptotic thymocytes were prepared with $\gamma$-irradiation (1500 rad) and used in for $4 \mathrm{~h}$. PKH26-labeled DCEK transfectants (red) were coincubated with CFSE-labeled apoptotic thymocytes (green) for $2 \mathrm{~h}$ at $4{ }^{\circ} \mathrm{C}$ at a $1: 1$ ratio, and apoptotic cell binding was assessed by two-color FACS analysis. (e) As in (d), but both cells were coincubated either for $30 \mathrm{~min}$ or for $2 \mathrm{~h}$ at $37^{\circ} \mathrm{C}$ at a $1: 1$ ratio

DCEK_SIGN-R1 (Figure 4b). To verify the role of C1q in enhancing the binding sensitivity of SIGN-R1 to apoptotic cells, the experiment was performed at $1: 1$ and $1: 4$ ratios of DCEKs-to-apoptotic thymocytes. C1q enhanced the binding of SIGN-R1 to apoptotic cells more dramatically at the $1: 1$ ratio than at the $1: 4$ ratio (Figure $4 \mathrm{c}$ ). When purified C1q was replaced with normal mouse serum as a source of $\mathrm{C} 1 \mathrm{q}$ (66 $\mu \mathrm{g} / \mathrm{ml}$ in mouse serum), apoptotic cell binding to DCEK_SIGN-R1 also increased (Figure 4d).
Because SIGN-R1 is also expressed on resident peritoneal macrophages,${ }^{34}$ the role of SIGN-R1 on peritoneal macrophages was assessed in apoptotic cell ingestion. The blocking of SIGN-R1 by 22D1 significantly reduced apoptotic cell ingestion by peritoneal macrophages compared with control hamster IgG (Figure 4e, left). When the same experiments were performed with C1q-deficient mouse serum, a minor reduction in apoptotic cell ingestion was observed in both 22D1- or control IgG-treated peritoneal macrophages 
a

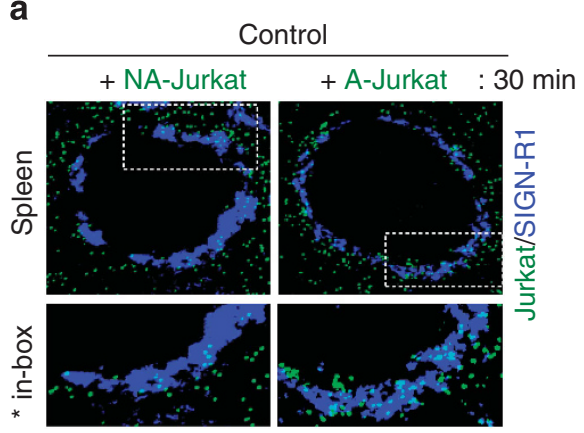

b

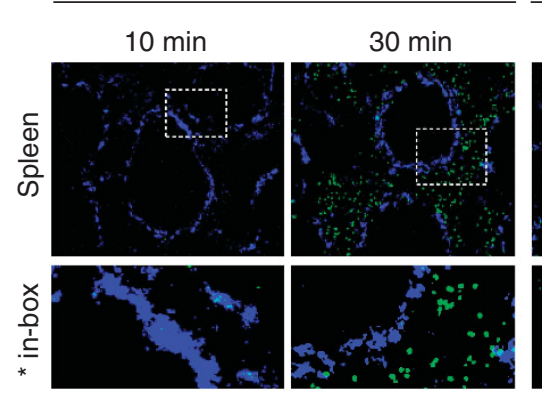

+ NA-Thy
+ A-Thy

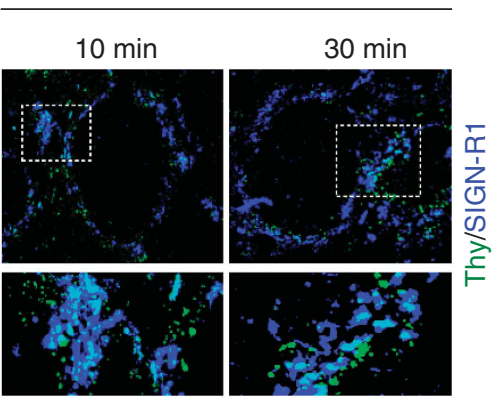

C

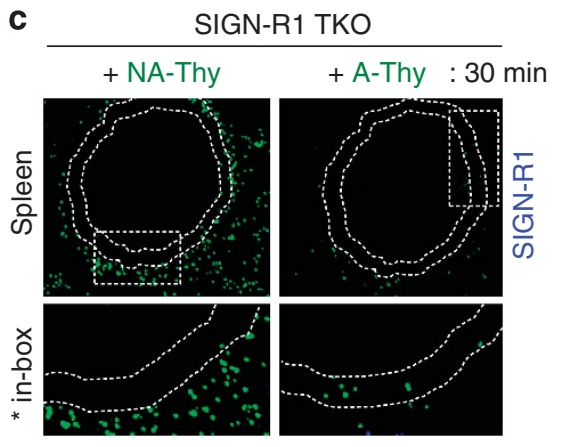

d

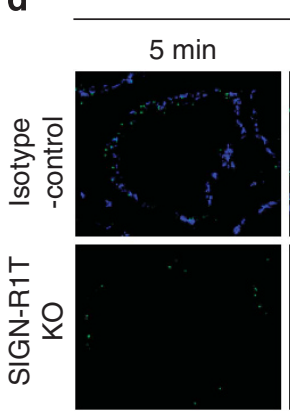

+ A-Thy

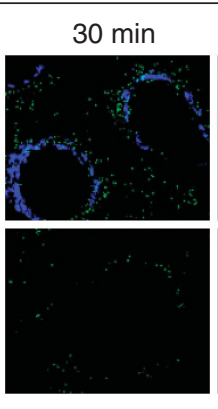

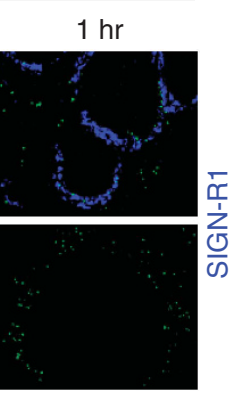

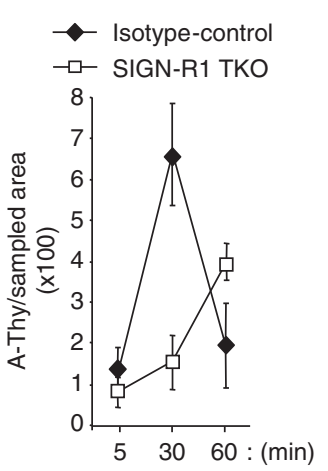

Figure 3 Initial binding of apoptotic cells to SIGN-R1 ${ }^{+}$macrophages in the splenic marginal zone (MZ) in vivo. (a) Apoptotic Jurkat T cells were prepared as in Figure 1a. CFSE-labeled nonapoptotic (NA-Jurkat) or apoptotic Jurkat (NA-Jurkat) T cells $\left(5 \times 10^{7}\right.$; green) were intravenously injected into mice for 30 min, and spleen sections were immunostained for SIGN-R1 (blue). (b) As in (a), but $1 \times 10^{8}$ nonapoptotic or apoptotic thymocytes were injected into C57BL/6 mice for 10 or 30 min. Apoptotic thymocytes were prepared as in Figure 1b. (c) As in (b), but both thymocytes were intravenously injected into SIGN-R1 TKO six mice that had been treated $24 \mathrm{~h}$ earlier with $200 \mu \mathrm{g}$ of hamster anti-SIGN-R1 mAb (Clone 22D1). (d) As in (b), but CFSE-labeled apoptotic thymocytes were intravenously injected into control (hamster lgG) or SIGN-R1 TKO mice for $5 \mathrm{~min}, 30 \mathrm{~min}$, or $1 \mathrm{~h}$. Apoptotic cells were counted in five areas of each spleen section from three independent experiments, and average numbers were calculated (right)

(Figure 4e, right), emphasizing the synergistic role of SIGN$\mathrm{R} 1$ and $\mathrm{C} 1 \mathrm{q}$ in apoptotic cell ingestion.

SIGN-R1 mediates C3 deposition on apoptotic cells in the MZ. Since SIGN-R1 directly mediates the classical complement pathway against $S$. pneumoniae by interacting with $\mathrm{C} 1 \mathrm{q},{ }^{26}$ these two molecules may contribute to complement deposition on apoptotic cells. To verify this possibility, DCEK_WT and DCEK_SIGN-R1 were incubated with apoptotic thymocytes (green) with or without 10\% normal mouse serum. After washing cells, we performed immunostaining for C1q, C4, and C3 (red) in the classical complement pathway. Based on the FACS analysis, the cell population was classified into two groups: R1 (for DCEKs alone) and R2 (for apoptotic cell-bound DCEKs) (Supplementary Figure 4a), and both groups were analyzed for the deposition of each complement. The deposition of $\mathrm{C} 1 \mathrm{q}$ or $\mathrm{C} 4$ was obvious on both groups only with DCEK_SIGN-R1 (Figure 5a, right two columns, first and second rows). C3 was dramatically deposited in both groups of DCEK_SIGNR1, showing higher levels of deposition in R2 than in R1 (Figure 5a, right two columns, third row). C3 deposition on both groups of DCEK_WT was likely to be caused by other complement activation pathways, ${ }^{17,35}$ because there were no deposition of C1q and C4 (Figure 5a, left two columns).

To examine C3 deposition on apoptotic cells in vivo, apoptotic thymocytes (green) were intravenously injected into control mice for $10 \mathrm{~min}$, and spleen sections were immunostained for $\mathrm{C} 3$ or control nonreactive IgG (red), and SIGN-R1 (blue). No red signal was detected on apoptotic cells with nonreactive IgG (Figure 5b, left column, and the $10 \times$ power image in Supplementary Figure 4b, left). However, C3 deposition on apoptotic cells was significant on SIGN-R1 ${ }^{+}$ macrophages of the MZ (Figure 5b, right column, its $10 \times$ power image in Supplementary Figure $4 b$, right, and $10 \times$ power images of other areas in Supplementary Figure 4c). These results strongly indicate that C3 deposition was mediated by SIGN-R1 on apoptotic cells in vivo. To verify these findings, we performed similar immunostaining on adjacent spleen sections using another C3 antibody (red) and obtained the same results (Figure $5 \mathrm{c}$ and $10 \times$ power image of another area in Supplementary Figure 4d). To confirm C3 deposition on apoptotic cells in the spleen, the experiment described in Figure $5 \mathrm{~b}$ was also performed in C3depleted mice (Supplementary Figure 4e). As expected, no C3 deposition was observed on apoptotic cells in the MZ (Figure $5 \mathrm{~d}$ and its $10 \times$ power image in Supplementary Figure 4f) and in other splenic $M Z$ areas examined (Supplementary Figure $4 \mathrm{~g}$ ), even though SIGN-R1 ${ }^{+}$macrophages were still present. To confirm these results, the experiment described in Figure 5b was performed in SIGN-R1 $\mathrm{KO}$ mice at $30 \mathrm{~min}$ when a significant number of apoptotic cells accumulated in the MZ of the SIGN-R1 KO mice (Figure 3d). As expected, no $\mathrm{C} 3$ deposition was observed in spleens of 


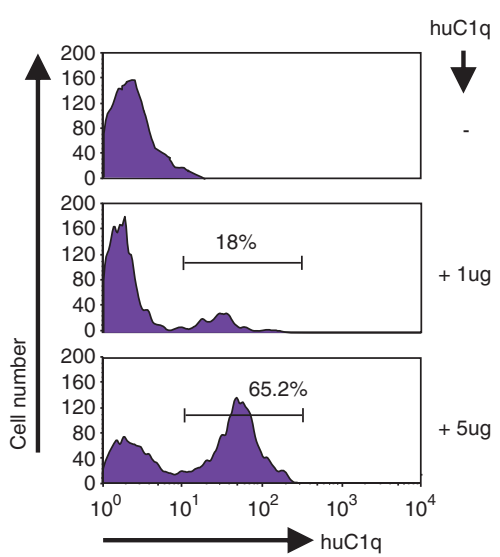

b

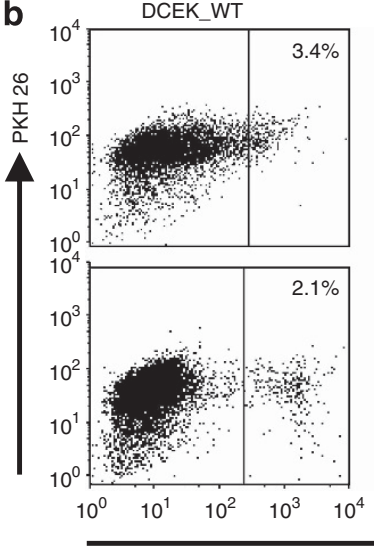

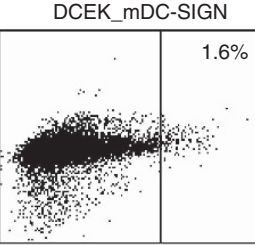

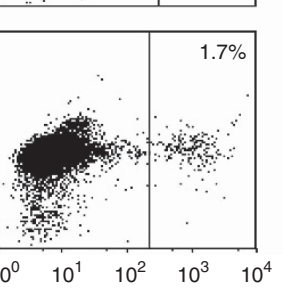

DCEK_SIGN-R1

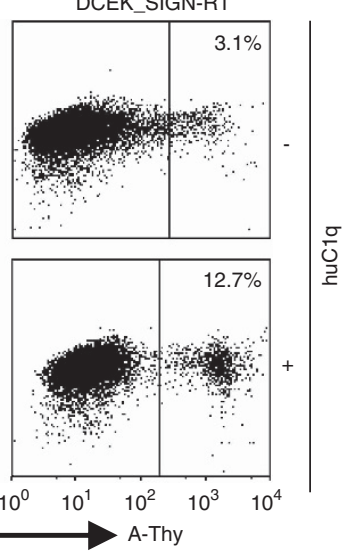

C

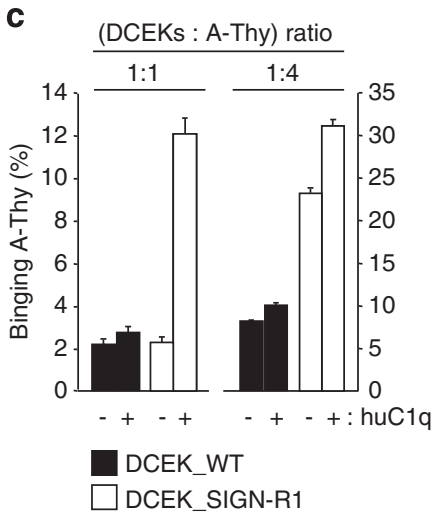

d

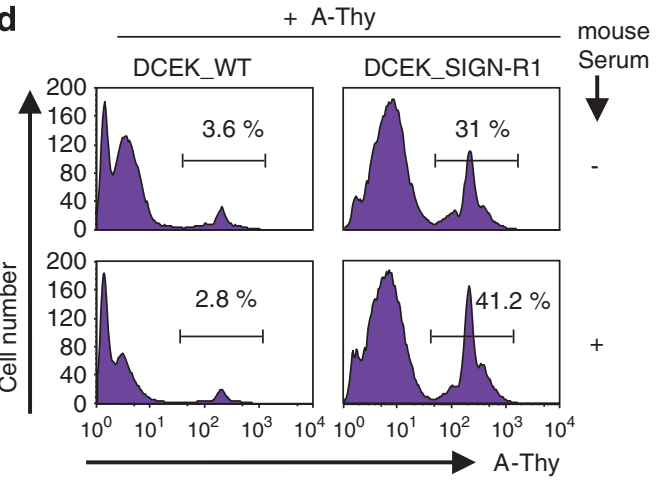

e
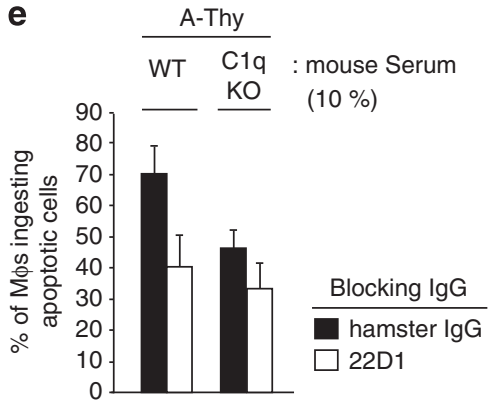

Figure $4 \mathrm{C} 1 \mathrm{q}$ enhances SIGN-R1 binding to apoptotic cells in vitro. (a) Apoptotic thymocytes were prepared as in Figure 1b. Apoptotic thymocytes were incubated with 1 or $5 \mu \mathrm{g}$ of purified human $\mathrm{C} 1 \mathrm{q}$ (huC1q) for $30 \mathrm{~min}$ at $37^{\circ} \mathrm{C}$ and immunostained for $\mathrm{C} 1 \mathrm{q}$, which was followed by a FACS analysis. The percentage of C1q-binding apoptotic thymocytes was calculated. (b) Apoptotic thymocytes were prepared as in Figure 2d. CFSE-labeled apoptotic thymocytes (green) were incubated with or without $15 \mu \mathrm{g}$ of purified human $\mathrm{C} 1 \mathrm{q}$ for $6 \mathrm{~h}$ at $4^{\circ} \mathrm{C}$ and then coincubated with PKH26-labeled DCEKs (red) for $30 \mathrm{~min}$ at $37^{\circ} \mathrm{C}$ at a 1:1 ratio, which was followed by a two-color FACS analysis. The percentage of DCEKs bound to apoptotic cells was calculated. (c) As in (b), but both cells were coincubated at 1:1 or 1:4 ratios of DCEKs-to-apoptotic cells for 30 min at $37^{\circ} \mathrm{C}$. DCEKs bound to apoptotic cells were quantified from three independent experiments by FACS analysis, and average counts were calculated (black bars for DCEK_WT, empty bars for DCEK_SIGN-R1). (d) DCEK_WT or_SIGN-R1 cells were incubated with CFSE-labeled apoptotic cells at a 1:4 ratio with or without 1\% normal mouse serum for $30 \mathrm{~min}$ at $37^{\circ} \mathrm{C}$, which was followed by a FACS analysis. The percentage of DCEKs bound to apoptotic cells was calculated. (e) Resident peritoneal macrophages (pM $\phi s$ ) were obtained from either nonreactive hamster IgG-treated or 22D1 anti-SIGN-R1 mAb-treated mice (100 $\mu \mathrm{g}$, intraperitoneal, $24 \mathrm{~h})$ and coincubated with CFSE-labeled apoptotic thymocytes in the presence of $10 \%$ WT or C1q KO mouse serum for $30 \mathrm{~min}$ at $37^{\circ} \mathrm{C}$. Peritoneal macrophages were immunostained with phycoerythrin-conjugated anti-CD11b mAb and observed with a fluorescent microscope. The percentage of $\mathrm{CD} 11 \mathrm{~b}^{+} \mathrm{pM} \phi \mathrm{s}$ ingurgitating apoptotic thymocytes was calculated from three independent experiments

SIGN-R1 KO mice (Figure 5e, the $10 \times$ power image in Supplementary Figure $4 \mathrm{~h}$, and other splenic areas examined in Supplementary Figure 4i).

C3 deposition on apoptotic cells in the liver is likely to be mediated by SIGN-R1 ${ }^{+}$macrophages in the MZ. C3 deposition on apoptotic cells was examined in livers prepared from mice used in Figure 5. As reported in previous studies, ${ }^{16,17,20}$ C3 deposition was evident on apoptotic cells in the liver of control mice (Figure 6a, first row, and the other areas in Supplementary Figure 5a), which was further confirmed by no C3 signal with nonreactive rabbit IgG (Supplementary Figure 5b). However, C3 deposition was barely found on a few apoptotic cells in the liver of the SIGN-R1 $\mathrm{KO}$ mice (Figure 6a, third row, and the other area in Supplementary Figure 5d), and not in the liver of C3-depleted mice (Figure 6a, second row, and the other areas in Supplementary Figure $5 \mathrm{c}$ ). The quantification data of C3-deposited apoptotic cells was presented (Figure 6b, also see the representative counting area in Supplementary Figure 5e).

Delayed clearance of apoptotic cells in SIGN-R1 KO mice induces abnormal cytokine production in vivo. The efficiency of apoptotic cell clearance was directly compared in spleens and livers of control, C3-depleted, and SIGN-R1 $\mathrm{KO}$ mice $1 \mathrm{~h}$ after an intravenous injection of apoptotic cells (green), when most of the circulating apoptotic cells were cleared in control mice (Figure 3d). It was obvious that apoptotic cell clearance was significantly delayed in spleens of C3-depleted and SIGN-R1 KO mice compared with the spleen of control mice (Figure 7a). The efficiency of apoptotic cell clearance was also examined in livers of the above mice in Figure $7 \mathrm{a}$ and a similar pattern was observed in livers (Figure 7b).

The abnormal production of pro- and anti-inflammatory cytokines is induced by delayed clearance of apoptotic 
a

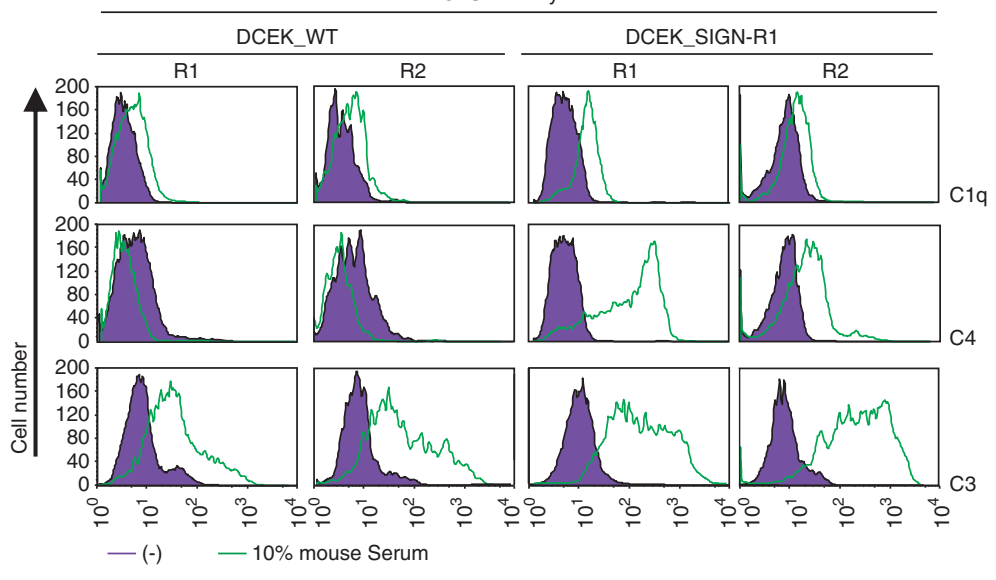

C

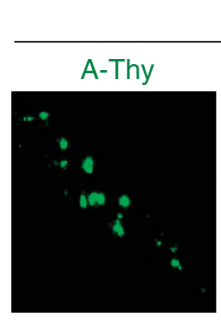

d

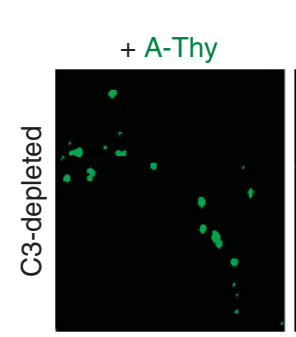

+ CFSE-A-Thy
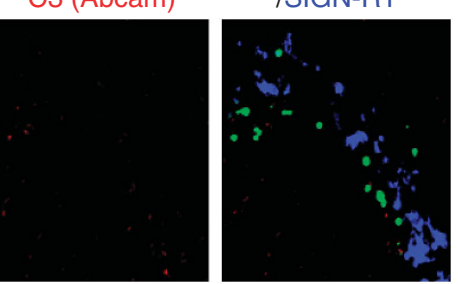

e b
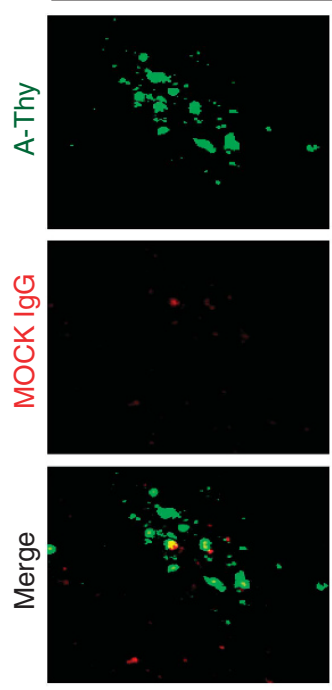
SIGN-R1
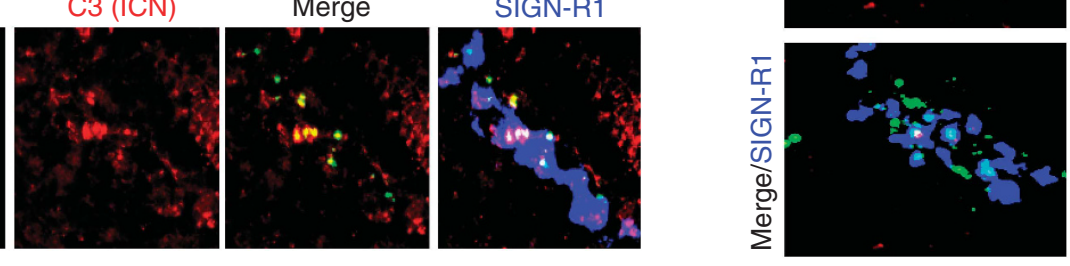

\section{CFSE-A-Thy}
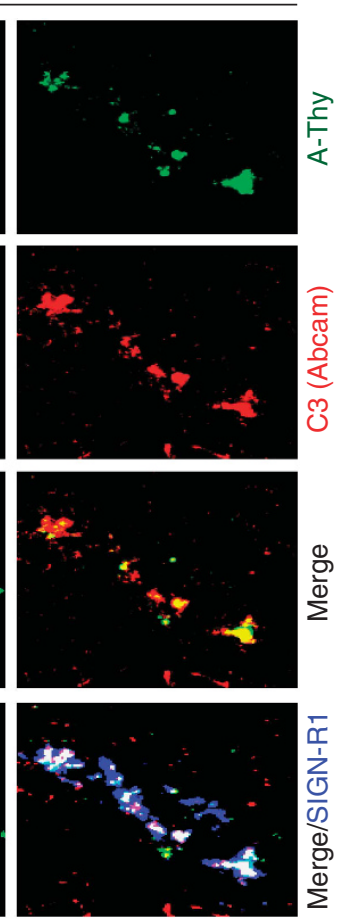

Merge/ SIGN-R1

+ A-Thy

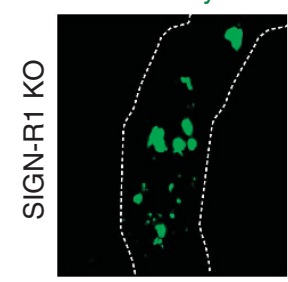

C3 (Abcam)

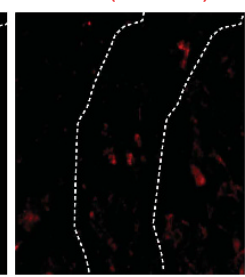

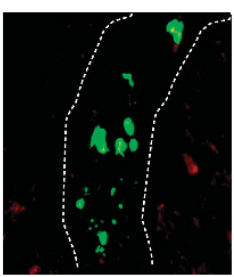

Figure 5 SIGN-R1 mediates complement C3 deposition on apoptotic cells in vitro and in vivo. (a) DCEKs and $1 \times 10^{8} \mathrm{CFSE}$-apoptotic thymocytes were coincubated with or without $10 \%$ normal mouse serum for 30 min at $37^{\circ} \mathrm{C}$. After washing extensively, cells were immunostained for $\mathrm{C} 1 \mathrm{q}, \mathrm{C} 4$, and C3. Region 1 or Region 2 (R1 or R2) indicate DCEKs only or DCEKs bound to apoptotic cells, respectively (see also Supplementary Figure 4a). (b) CFSE-labeled apoptotic thymocytes $\left(1 \times 10^{8}\right.$; green) were intravenously injected into control mice for $10 \mathrm{~min}$, and spleen sections were immunostained with nonreactive hamster IgG or anti-C3 antibody (red, Abcam). SIGN-R1 ${ }^{+}$macrophages were immunostained with anti-SIGN-R1 mAb (Clone 22D1, blue). (c) As in (c), but C3 was immunostained with a different anti-C3 antibody (red, ICN). (d) As in (b), but spleen sections from C3-depleted mice were immunostained. (e) As in (b), but $10 \mathrm{~min}$ after the intravenous injection of apoptotic cells into SIGN-R1 KO mice, their spleen sections were immunostained

cells. $^{36,37}$ Therefore, cytokine production was examined in the spleen and liver of control and SIGN-R1 KO mice $1 \mathrm{~h}$ after the intravenous injection of apoptotic cells. We found a significant induction of the anti-inflammatory cytokine, TGF- $\beta$ and a decrease in the pro-inflammatory cytokine, TNF- $\alpha$, in spleens of control mice (Figure 7c, upper first and second graph, black bars). However, opposite results were obtained in spleens of SIGN-R1 KO mice where a reduction of TGF- $\beta$ and a minor induction in TNF- $\alpha$ production were seen (Figure 7c, upper first and second graph, empty bars). A similar pattern of abnormal cytokine production was observed in livers of the SIGN-R1 KO mice, except for the significant induction of TNF- $\alpha$ (Figure 7c, lower first and second graph). In addition, the pro-inflammatory cytokine, IL-6, were higher in both tissues of SIGN-R1 KO mice (Figure 7c, third graph). However, no significant changes were seen in the level of IL-10 in either mouse group (Supplementary Figure 6c). All of these results were in agreement with those of previous studies. ${ }^{10,38-40}$

\section{MRL-MpJ/SIGN-R1 TKO mice generate higher levels of} anti-double-stranded (ds) and anti-single-stranded (ss) DNA antibodies. We next examined if SIGN-R1 deficiency predisposed mice to autoimmunity due to the delayed clearance of circulating apoptotic cells. The generation of autoantibodies, such as anti-dsDNA and anti-ssDNA, was compared between the isotype control injected and SIGN-R1 TKO (22D1 injected) mice, which were generated in autoimmune-prone MRL/MpJ mice (MRL/MpJ_hamster IgG or MRL/MpJ_SIGN-R1 TKO mice, respectively). After four intravenous injections of apoptotic thymocytes $\left(10^{7}\right.$ cells/ mouse) at 1-week interval, MRL/MpJ_SIGN-R1 TKO mice showed a significant increase in levels of anti-dsDNA 
a
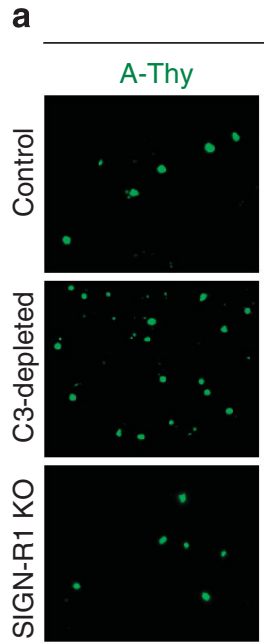

Liver
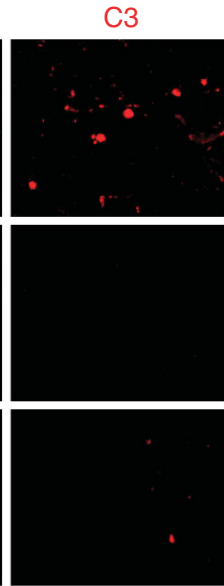
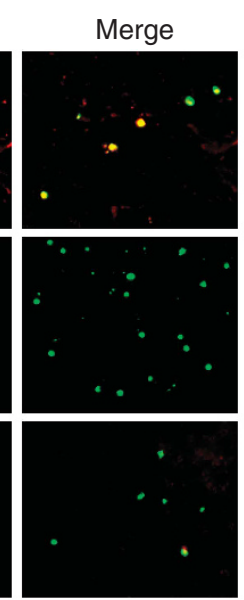
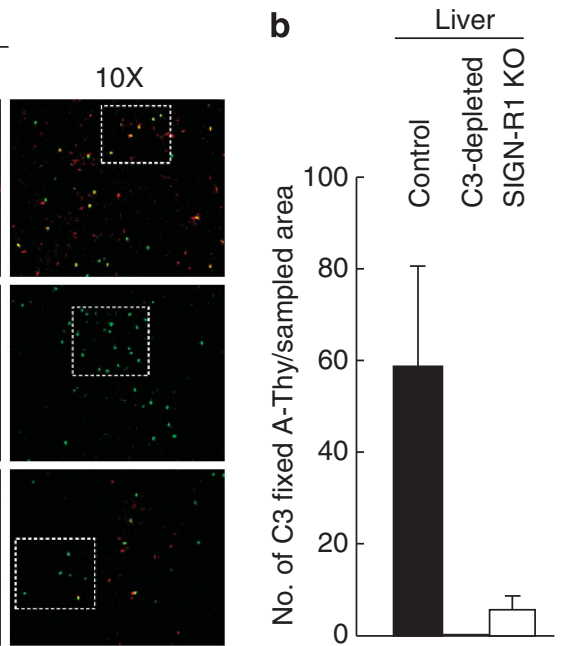

Figure 6 SIGN-R1 mediates C3 deposition on apoptotic cells in the liver. (a) CFSE-labeled apoptotic thymocytes ( $1 \times 10^{8}$; green) were injected into control, SIGN-R1 KO, and C3-depleted mice for $10 \mathrm{~min}$, and the liver sections were immunostained for $\mathrm{C} 3$ (red). Each inset of the respective $10 \times$ power images was enlarged and presented in single or merged color. (b) As in (a), but the percentage of C3-deposited apoptotic cells of the total apoptotic cells in the respective livers was calculated from three independent experiments

antibodies ( $\lg G)$ as early as 4 weeks after the first intravenous injection compared with MRL/MpJ_hamster IgG mice (Figure 7d). In addition, MRL/MpJ_SIGN-R1 TKO mice also generated more anti-ssDNA antibodies (lgG) than in MRL/ MpJ_hamster IgG mice as well (Supplementary Figure 6d).

\section{Discussion}

MZMs mediate not only the efficient clearance of circulating apoptotic cells, but also the induction of immune tolerance. ${ }^{10,15}$ Complement $\mathrm{C} 3$ is essential for the rapid clearance of apoptotic cells by opsonizing apoptotic cells and facilitating the phagocytic function of macrophages. ${ }^{16,17}$ In the present study, we demonstrated that SIGN-R1 specifically entrapped apoptotic cells in the MZ, but not live cells nor latex beads (Figures 3a and b; Supplementary Figure 3, left row). Also, it was identified that SIGN-R1 specifically increased C3 deposition on apoptotic cells depending on the presence of $\mathrm{C} 1 \mathrm{q}$ and $\mathrm{C} 4$ in vitro (Figure $5 \mathrm{a}$, right two columns, respectively) within a few minutes in the spleen (Figures 4 and 5). These results suggest that there is a SIGN-R1mediated classical complement pathway for apoptotic cell clearance in vivo, defining a specific role of SIGN-R1 ${ }^{+}$ macrophages among MZMs. The deposition of complements such as C1q, MBL and C3 on apoptotic cells and complement activation are events that mainly take place during the late phase of apoptotic cells. ${ }^{19,22-24,41}$ However, our findings are noteworthy in that the SIGN-R1-mediated C3 deposition might be early initiated within a few minutes, thus enhancing the rapid opsonization of $\mathrm{C} 3$ fragments such as $\mathrm{C} 3 \mathrm{~b}$ and $\mathrm{iC} 3 \mathrm{~b}$ on apoptotic cells (Figure 5).

Even though SIGN-R1 itself can directly bind to apoptotic cells, C1q dramatically increased apoptotic cell binding to SIGN-R1 transfectants at a $1: 1$ ratio of SIGN-R1 transfectants-to-apoptotic cells, at which these cells did not otherwise bind (Figures $4 b-d$, respectively). Also, C1q enhanced apoptotic cell clearance by SIGN-R1 ${ }^{+}$peritoneal macrophages (Figure 4e). These results strongly suggest that the intimate relationship between SIGN-R1 and C1q dramatically enhances the initial recognition of the low frequency of apoptotic cells in the $\mathrm{MZ}$, directly leading to the rapid activation of the classical complement pathway, as shown in our previous report. ${ }^{26}$ Also, this was in agreement with earlier reports where complement activation and opsonization of apoptotic cells were significantly dependent on the ratio of phagocytes-to-apoptotic cells during enhanced clearance of apoptotic cells. ${ }^{42}$

C3-deposited apoptotic cells were found in the liver of control mice (Figure 6, upper row), but significantly reduced in the liver of SIGN-R1 KO mice (Figure 6a, bottom row and Figure $6 \mathrm{~b}$, right bar). This result was entirely unexpected because SIGN-R1 is not expressed in the liver (Supplementary Figure 3a, middle column). ${ }^{13,43,44}$ Recently, it was suggested that besides a direct capture mechanism mediated by MZMs, other active mechanisms must be involved in the apoptotic cell clearance, likely to locally and systemically act distal to the spleen, because MZM numbers are low approximately comprising $<1 \%$ splenocytes. ${ }^{29,45}$ SIGN-R1 ${ }^{+}$macrophage numbers are much lower than MZMs, comprising $<0.05 \%$ splenocytes. ${ }^{13,46}$ Blood entered the spleen via the splenic artery eventually drains into the liver circulation. ${ }^{47}$ And, the liver plays a dominant role in the clearance of C3-opsonized particles including apoptotic cells through a variety of complement receptors on liver cells. ${ }^{48-50}$ Consequently, there might be a systemic clearance of apoptotic cells in vivo, especially involving the cooperative roles between splenic SIGN-R1 ${ }^{+}$macrophages and hepatic macrophages, representatively $\mathrm{F} 4 / 80_{ \pm}$Kupffer cells (Supplementary Figure 6b). Also, this possibility might additionally explain the reasons of the severely delayed clearance of dying cells and the failure to induce tolerance when MZMs have been transiently deleted. ${ }^{9}$

The binding and ingestion of apoptotic cells by phagocytes results in activating anti-inflammatory responses and 
a
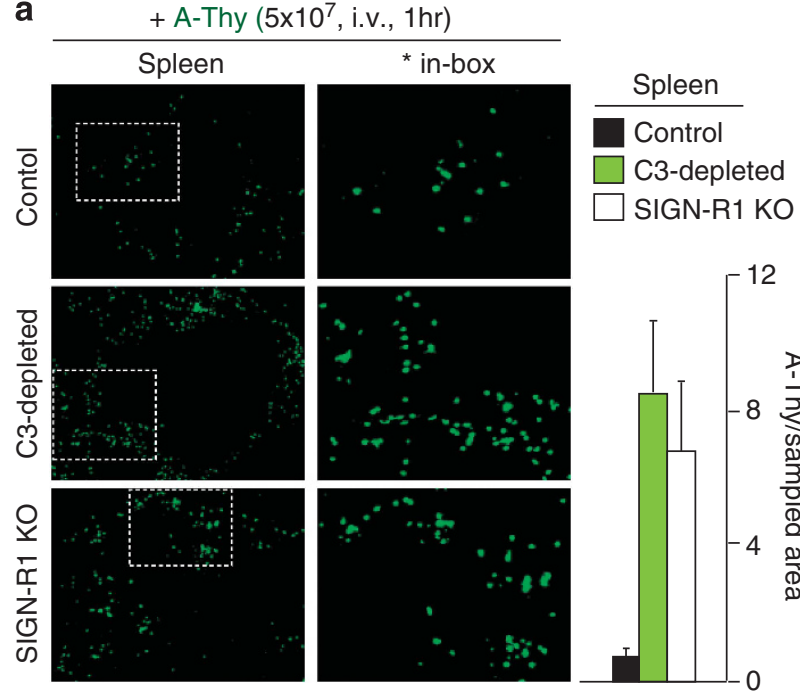

(X100) b
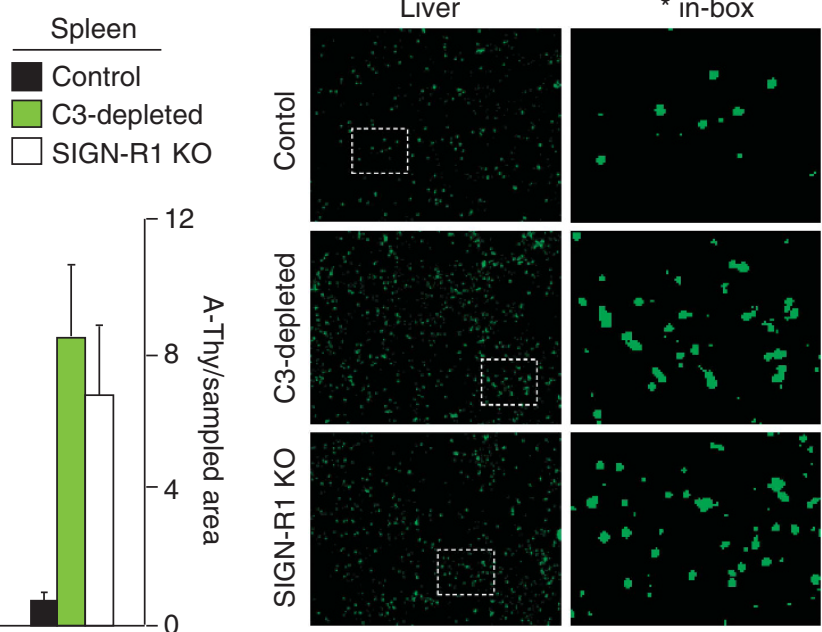
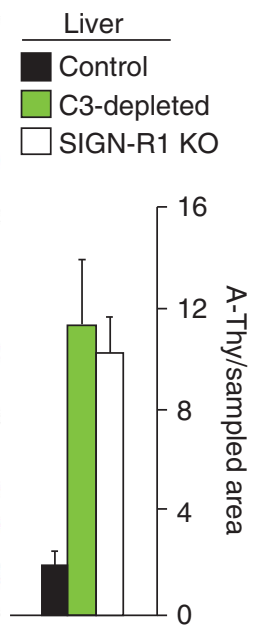

(X100)
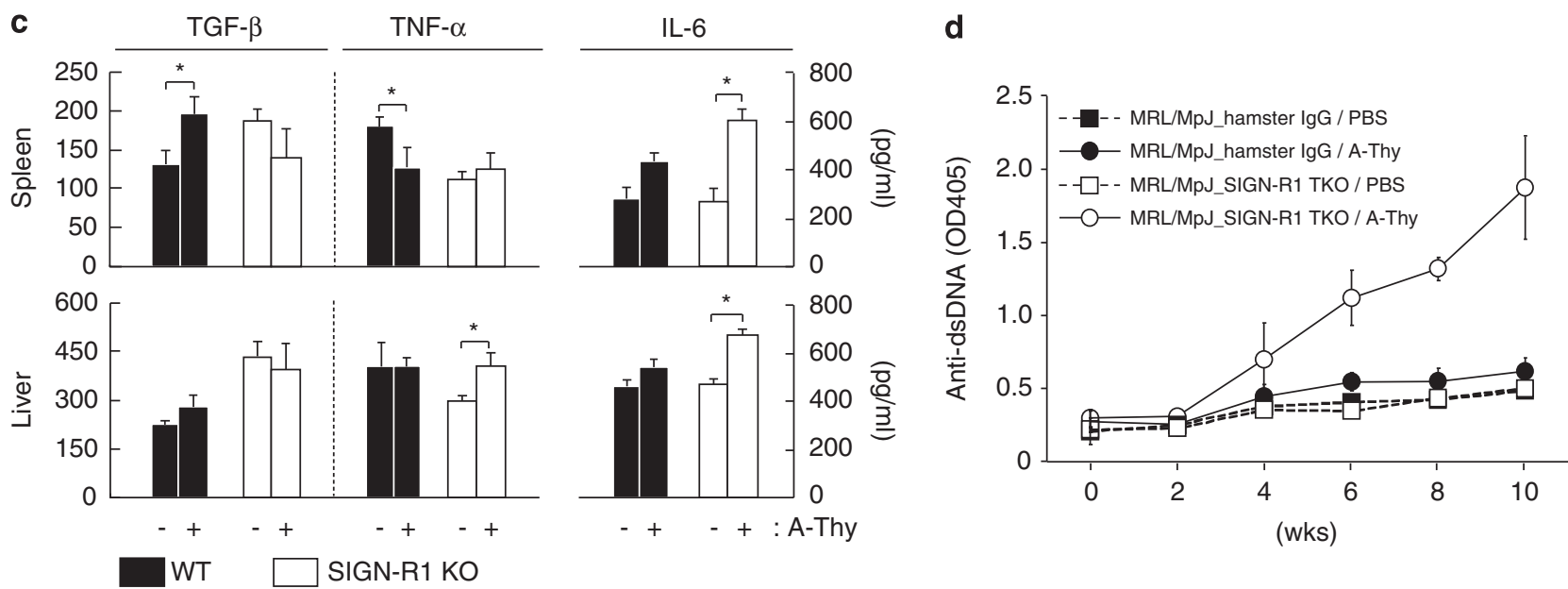

Figure 7 SIGN-R1 deficiency delays the clearance of apoptotic cells in vivo, inducing aberrant cytokine production and the generation of autoantibodies. (a) CFSE-labeled apoptotic thymocytes $\left(1 \times 10^{8}\right.$, green) were intravenously injected into control, SIGN-R1 KO, and C3-depleted mice for $1 \mathrm{~h}$. Apoptotic cells from the respective spleen sections were detected by fluorescent microscopy, and the representative areas are presented in insets. The average number of apoptotic cells was calculated from eight sections per mouse from the four different experiments (right graph). (b) As in (a), but apoptotic thymocytes were detected and counted from the livers. (c) Control or SIGN-R1 KO mice were intravenously injected with PBS or $5 \times 10^{7}$ apoptotic cells for $1 \mathrm{~h}$ (black or empty bars, respectively), and the endogenous levels of TGF- $\beta$, TNF- $\alpha$, and IL- 6 were examined from tissue lysates of spleens or livers by ELISA. The bars are the mean values for seven mice per group. ${ }^{*} P<0.05$ as determined by Student's unpaired $t$-test. (d) MRL/MpJ mice were intravenously injected with $100 \mu \mathrm{g}$ of nonreactive hamster IgG or 22D1 anti-SIGN-R1 mAb for 24 h (MRL/MpJ_hamster IgG or MRL/MpJ_SIGN-R1 TKO, respectively), which was followed by PBS or four intravenous injections of apoptotic thymocytes ( $\left.10^{7} \mathrm{celll} / \mathrm{mouse}\right)$ at 1 -week interval. Sera from both mice were collected at the indicated time points and assessed for the presence of anti-dsDNA Ab (IgG), as described in the Materials and methods. The data shown are mean \pm S.E.M. and representative plots of two to three experiments, in which the error bars represent S.E.M. ( $n=5$ mice per group)

inhibiting pro-inflammatory responses in control mice. 9,51,52 $^{9}$ The defect of clearing apoptotic cells in both spleen and liver of SIGN-R1 KO mice (Figures $7 \mathrm{a}$ and $\mathrm{b}$; Supplementary Figures $3 b$ and $6 c$, respectively) resulted in the aberrant secretion of cytokines in vivo (Figure 7c). Also, autoantibodies, like anti-dsDNA and anti-ssDNA, were significantly increased in the SIGN-R1 TKO mice compared with control mice (Figure 7d; Supplementary Figure 6d). Recently, it was shown that SIGN-R1 directly mediates the anti-inflammatory effects of intravenous immunoglobulin in a local and systemic manner, ${ }^{28,29}$ even though splenic SIGN-R1 ${ }^{+}$macrophage numbers are extremely low compared with MZM numbers $(<0.05 \%){ }^{13,46}$ Therefore, our findings suggested that splenic
SIGN-R1 ${ }^{+}$macrophages are essential for the immune tolerance against apoptotic cells in vivo.

In conclusion, SIGN-R1 in the MZ rapidly accelerates C3 deposition on circulating apoptotic cells by interacting with $\mathrm{C} 1 \mathrm{q}$, thus promoting the systemic clearance of apoptotic cells and maintaining immune tolerance in vivo. These findings are valuable to identify an integral role of SIGN-R1 in apoptotic cell clearance by linking the recognition of apoptotic cells, their opsonization of complements, and the induction of immune tolerance. Also, these findings provide an insight to understand the role of homologous human C-type lectins, such as DC-SIGN and liver/lymph node-specific-SIGN (L-SIGN, DC-SIGN-R; CD209L), in apoptotic cell clearance. 


\section{Materials and Methods}

Mice, cells, and reagents. C57BL/6 mice were purchased from B\&K Universal Limited (Hull, England). SIGN-R1 (CD209b) KO mice were kindly provided by The Consortium for Functional Glycomics (CFG; http://www.functionalglycomics.org). SIGN-R1 TKO or control mice were generated by the intravenous injection of $100 \mu \mathrm{g}$ of 22D1 antibody or isotype hamster IgG for $48 \mathrm{~h}$ and 22D1 antibody selectively and transiently depleted surface SIGN-R1 molecule but not SIGN-R1 $1^{+}$macrophages in the splenic MZ, permitting analysis of its function in vivo, as in a previous report. ${ }^{33}$ To obtain C3-depleted mice, control mice were injected intraperitoneally with $60 \mathrm{U} / \mathrm{kg}$ of cobra venom factor (CVF) 1 day prior to the experimental challenge. Six-week-old MRL/MpJ mice (The Jackson Laboratory, Bar Harbor, ME, USA). were used for the autoimmune susceptibility study. Mice were maintained under specific pathogen-free conditions until their use at $6-10$ weeks of age. All protocols for this study were approved by the Institutional Animal Care and Use Committee (IACUC) of Konkuk University (Permit Number: KU11107). DCEK, a mouse L-cell fibroblast line, and Jurkat cells were cultured in RPMI-1640 Medium and CHO cells in Dulbecco's Modified Eagle Medium, supplemented with $10 \%$ fetal bovine serum, 100 units $/ \mathrm{ml}$ penicillin G, and $100 \mu \mathrm{g} / \mathrm{ml}$ streptomycin, respectively. Stable DCEK transfectants expressing CDNA for mDCSIGN or SIGN-R1 (DCEK_mDC-SIGNS and_SIGN-R1 in the figures, respectively) and stable $\mathrm{CHO}$ transfectants expressing cDNA for Neo, MARCO or SIGN-R1 (CHO_Neo,_MARCO or_SIGN-R1 in the figures, respectively) were used. Resident peritoneal macrophages were obtained by lavage of the peritoneal cavity of mice with $8 \mathrm{ml}$ of cold sterile saline. The following materials were purchased: efOVA (Seikagaku Corporation, Tokyo, Japan), CFSE, paraformaldehyde, PKH26, transferrin, dexamethasone, PI, thymus DNA (Sigma-Aldrich, St Louis, MO, USA), purified C1q and CVF (Quidel, Santa Clara, CA, USA), Alexa Fluor 568 antibody labeling kit and EZLinkTM NHS-Biotin (Thermo Fisher Scientific Inc., Rockford, IL, USA), Hoechst 33258 (Life Technologies, Grand Island, NY, USA), Cell Lysis Buffer (Cell Signaling Technology, Danvers, MA, USA), phenylmethylsulfonyl fluoride (PMSF), Quantikine Colorimetric Sandwich ELISAs (R\&D Systems, Minneapolis, MN, USA), and Tissue-Tek OCT compound (Sakura Finetek Japan Co., Tokyo, Japan). Purified soluble SIGN-R1 protein was prepared as described in a previous report. ${ }^{33}$ Antibodies or purified proteins were biotinylated with EZLinkTM NHS-Biotin for $2 \mathrm{~h}$ at $4{ }^{\circ} \mathrm{C}$ or conjugated with Alexa Fluor according to the manufacturer's instructions. C1q-deficinet mouse serum was obtained from C1q KO mice and stored at $-70^{\circ} \mathrm{C}$ until use as fresh serum.

Antibodies and microscopy. The rabbit polyclonal or hamster monoclonal antibody against SIGN-R1 (PAb-C13 or 22D1, respectively) were described previously. ${ }^{13,33}$ The following antibodies were purchased: FITC- or HRPconjugated mouse C3 and mouse C4 (ICN Pharmaceuticals, Costa Mesa, CA, USA), human C3 (Abcam, Cambridge, MA, USA), total hamster IgG (Jackson Immunoresearch Laboratories, West Grove, PA, USA), MARCO (ED31 rat IgG1 $\mathrm{mAb}, \mathrm{AbD}$ SeroTec, UK), Annexin-V and Polyclonal anti-human C1q (Abcam), monoclonal anti-mouse $\mathrm{C} 1 \mathrm{q}$ (7H8, Hycult Biotech, Uden, The Netherlands), double-stranded (ds) DNA, single-stranded (ss) DNA, TGF- $\beta$, TNF- $\alpha$, IL-6, and IL10 (R\&D Systems). As secondary reagents, we used HRP-, FITC-, Phycoerythrin-, 7-amino-4-methyl-coumarin-3-acetic acid-, or Alexa Fluor-conjugated donkey antichicken IgY, goat anti-hamster IgG, donkey anti-rabbit IgG, goat anti-rat $\lg G$, and HRP-conjugated streptavidin from Abcam, Jackson ImmunoResearch Laboratories, and Life Technologies Corporation. Cells or tissue sections were examined for fluorescence with a deconvolution microscope (Olympus Corp., Tokyo, Japan).

Generation of apoptotic cells and FACS analysis. A single-cell suspension of thymocytes from freshly isolated thymus or Jurkat $T$ cells were incubated with $3 \mu \mathrm{M}$ dexamethasone at a concentration of $10^{7} \mathrm{cell} / \mathrm{ml}$ in RPMI1640 media. After overnight incubation, apoptosis induction was confirmed with Annexin-V and PI staining, resulting in $>70 \%$ apoptotic cells. In some experiments, apoptosis was also induced in mouse thymocytes by exposure to $\gamma$-irradiation (1500 rad), which was followed by a 4-h culture in RPMI-1640/0.4\% BSA. DCEK transfectants or apoptotic cells were labeled with $5 \mathrm{mM}$ of CFSE for $30 \mathrm{~min}$ at $37^{\circ} \mathrm{C}$. Purified protein binding to apoptotic cells or apoptotic cell binding to DCEK transfectants were performed in $200 \mu \mathrm{l}$ of TC buffer $(10 \mathrm{mM}$ Tris- $\mathrm{HCl}$, $140 \mathrm{mM} \mathrm{NaCl}, 2 \mathrm{mM} \mathrm{CaCl}_{2}, 2 \mathrm{mM} \mathrm{MgCl}_{2}$, and $1 \% \mathrm{BSA}$ ) and followed by FACS analysis using a FACScan (Becton Dickinson, San Jose, CA, USA).

Fluorescent microscopic analysis. CFSE-labeled apoptotic thymocytes were incubated with Alexa568-conjugated proteins and were analyzed by fluorescent microscopy. CFSE-labeled DCEK transfectants on a cover glass were incubated with Hoechst 33258 -labeled apoptotic cells for $30 \mathrm{~min}$ at $37^{\circ} \mathrm{C}$, fixed with $1 \%$ paraformaldehyde and analyzed by fluorescent microscopy. After intravenously injecting CFSE-labeled thymocytes, spleen and liver tissues were snap frozen in OCT compound. After fixing with cold acetone, $10 \mu \mathrm{m}$ of the cryosections of the tissues were immunolabeled with 1, 2, or 3-color fluorescence and analyzed by fluorescent microscopy.

ELISA for cytokines and autoantibodies. Spleen and liver tissues were aseptically removed and homogenized in cell lysis buffer supplemented with $1 \mathrm{mM}$ PMSF. Endogenous production of cytokines was measured by doubleantibody sandwich ELISA with Quantitative immunoassays kit following the instruction's manual. To measure TGF- $\beta 1$, whole cell lysates were preactivated with acid according to the manufacturer's instructions prior to the ELISA assay. Anti-ds and anti-sS DNA antibodies were measured by ELISA, as described previously. ${ }^{53}$ Briefly, microtiter plates were coated with $10 \mu \mathrm{g} / \mathrm{ml}$ of calf thymus DNA. After incubating the plates with appropriately diluted tissue lysates, the assay was developed with alkaline phosphatase-labeled rat anti-mouse monoclonal antibody. The results are expressed in optical density (O.D.) $(450 \mathrm{~nm})$.

\section{Conflict of Interest}

The authors declare no conflict of interest.

Acknowledgements. We received valuable help from Dr. Park Seung Hwa, Department of Anatomy, College of Medicine, Chungju, Konkuk University, Republic of Korea for discussing blood circulation in the mouse. This work was supported by Mid-career Researcher Program through NRF grant funded by the MEST (Y-S Kang, R01-2008-000-20803-0), a grant from the Korea Healthcare Technology R\&D Project, Ministry for Health, Welfare \& Family Affairs, Republic of Korea (Y-S Kang, A080145), a grant from the Next-Generation BioGreen 21 Program (Y-S Kang, PJ009062), a grant from the National R\&D Program for Cancer Control, Ministry for Health and Welfare, Republic of Korea (Y Do, 1020120), and NIH/NIAID Exploratory/Development grant (Y Do, 1R21AI082331-01).

1. Lauber K, Blumenthal SG, Waibel M, Wesselborg S. Clearance of apoptotic cells: getting rid of the corpses. Mol Cell 2004; 14: 277-287.

2. Ravichandran KS, Lorenz U. Engulfment of apoptotic cells: signals for a good meal. Nat Rev Immunol 2007; 7: 964-974.

3. Gordon S. Pattern recognition receptors: doubling up for the innate immune response. Cell 2002; 111: 927-930.

4. Erwig LP, Henson PM. Clearance of apoptotic cells by phagocytes. Cell Death Differ 2008; 15: 243-250.

5. Firestein GS, Yeo M, Zvaifler NJ. Apoptosis in rheumatoid arthritis synovium. J Clinic Invest 1995; 96: 1631-1638.

6. Baumann I, Kolowos W, Voll RE, Manger B, Gaipl U, Neuhuber WL et al. Impaired uptake of apoptotic cells into tingible body macrophages in germinal centers of patients with systemic lupus erythematosus. Arthritis Rheum 2002; 46: 191-201.

7. Botto M, Dell'Agnola C, Bygrave AE, Thompson EM, Cook HT, Petry F et al. Homozygous C1q deficiency causes glomerulonephrities associated with multiple apoptotic bodies. Nat Genet 1998; 19: 56-59.

8. Schrijvers DM, De Meyer GR, Kockx MM, Herman AG, Martinet W. Phagocytosis of apoptotic cells by macrophages is impaired in atherosclerosis. Arterioscler Thromb Vasc Biol 2005; 6: 1256-1261.

9. Miyake $Y$, Asano K, Kaise H, Uemura M, Nakayama M, Tanaka M. Critical role of macrophages in the marginal zone in the suppression of immune responses to apoptotic cell-associated antigens. J Clin Invest 2007; 117: 2268-2278.

10. McGaha TL, Chen Y, Ravishankar B, van Rooijen N, Karlsson MC. Marginal zone macrophages suppress innate and adaptive immunity to apoptotic cells in the spleen. Blood 2011; 117: 5403-5412.

11. Kraal G. Cells in the marginal zone of the spleen. Int Rev Cytol 1992; 132: 31-74.

12. Kraal G, Mebius R. New insights into the cell biology of the marginal zone of the spleen. Int Rev Cytol 2006; 250: 175-215.

13. Kang YS, Yamazaki S, lyoda T, Pack M, Bruening SA, Kim JY et al. SIGN-R1, a novel C-type lectin expressed by marginal zone macrophages in spleen, mediates uptake of the polysaccharide dextran. Int Immunol 2003; 15: 177-186.

14. Miyake $\mathrm{Y}$, Asano K, Kaise H, Uemura M, Nakayama M, Tanaka M. Critical role of macrophages in the marginal zone in the suppression of immune responses to apoptotic cell-associated antigens. J Clin Invest 2007; 117: 2268-2278.

15. Morelli AE, Larregina AT, Shufesky WJ, Zahorchak AF, Logar AJ, Papworth GD et al. Internalization of circulating apoptotic cells by splenic marginal zone dendritic cells: 
dependence on complement receptors and effect on cytokine production. Blood 2003; 101 : 611-620.

16. Takizawa F, Tsuji S, Nagasawa S. Enhancement of macrophage phagocytosis upon iC3b deposition on apoptotic cells. FEBS Lett 1996; 397: 269-272.

17. Mevorach D, Mascarenhas JO, Gershov D, Elkon KB. Complement-dependent clearance of apoptotic cells by human macrophages. J Exp Med 1998; 188: 2313-2320.

18. Flierman R, Daha MR. The clearance of apoptotic cells by complement. Immunobio/ 2006 ; 212: 363-370.

19. Trouw LA, Blom AM, Gasque P. Role of complement and complement regulators in the removal of apoptotic cells. Mol Immunol 2008; 45: 1199-1207.

20. Korb LC, Ahearn JM. C1q binds directly and specifically to surface blebs of apoptotic human keratinocytes: complement deficiency and systemic lupus erythematosus revisited. $J$ Immunol 1997; 158: 4525-4528.

21. Navratil JS, Watkin SC, Wisnieski JJ, Ahearn JM. The globular heads of C1q specifically recognize surface blebs of apoptotic vascular endothelial cells. J Immuno/2001; 166: 3231-3239.

22. Ogden CA, deCathelineau A, Hoffmann PR, Bratton D, Ghebrehiwet B, Fadok VA et al. C1q and mannose binding lectin engagement of cell surface calreticulin and CD91 initiates macropinocytosis and uptake of apoptotic cells. J Exp Med 2001; 194: 781-795.

23. Nauta AJ, Trouw LA, Daha MR, Tijsma O, Nieuwland R, Schwaeble WJ et al. Direct binding of $\mathrm{C} 1 \mathrm{q}$ to apoptotic cells and cell blebs induces complement activation. Eur J Immunol 2002; 32: 1726-1736.

24. Nauta AJ, Raaschou-Jensen N, Roos A, Daha MR, Madsen HO, Borrias-Essers MC et al. Mannose-binding lectin engagement with late apoptotic and necrotic cells. Eur J Immunol 2003; 33: 2853-2863.

25. Roos A, Xu W, Castellano G, Nauta AJ, Garred P, Daha MR et al. Mini-review: a pivotal role for innate immunity in the clearance of apoptotic cells. Eur J Immunol 2004; 34: 921-929.

26. Kang YS, Do Y, Lee HK, Park SH, Cheong C, Lynch RM et al. A dominant complement fixation pathway for pneumococcal polysaccharides initiated by SIGN-R1 interacting with C1q. Cell 2006; 125: 47-58.

27. Lanoue A, Clatworthy MR, Smith P, Green S, Townsend MJ, Jolin HE et al. SIGN-R1 contribute to protection against lethal pneumococcal infection in mice. J Exp Med 2004; 6: 1383-1393.

28. Anthony RM, Wermeling F, Karlsson $\mathrm{MCl}$, Ravetch JV. Identification of a receptor required for the anti-inflammatory activity of IVIG. Proc Natl Acad Sci USA 2008; 105: 19571-19578.

29. Anthony RM, Nimmerjahn F, Ashline DJ, Reinhold VN, Paulson JC, Ravetch JV. Recapitulation of IVIG anti-inflammatory activity with a recombinant IgG Fc. Science 2008; 320: 373-376.

30. Bajenoff M, Narni-Mancinelli E, Brau F, Lauvau G. Visualizing early splenic memory CD8 + T cells reactivation against intracellular bacteria in the mouse. PLOS One 2010; 12: e11524.

31. Langeveld M, Gamadia LE, ten Berge IJ. T-lymphocyte subset distribution in human spleen. Eur J Clin Invest 2006; 36: 250-256.

32. Wermeling F, Chen Y, Pikkarainen T, Scheynius A, Winqvist O, Izui S et al. Class A scavenger receptors regulate tolerance against apoptotic cells, and autoantibodies against these receptors are predictive of systemic lupus. J Exp Med 2007; 204: 2259-2265.

33. Kang YS, Kim JY, Bruening SA, Pack M, Charalambous A, Pritsker A et al. The C-type lectin SIGN-R1 mediates uptake of the capsular polysaccharide of Streptococcus pneumoniae in the marginal zone of mouse spleen. Proc Natl Acad Sci USA 2004; 101 215-220

34. Taylor PR, Brown GD, Herre J, Williams DL, Willment JA, Gordon S. The role of SIGN-R1 ant the $\beta$-glucan receptor (Dectin-1) in the nonopsonic recognition of yeast by specific macrophages. J Immunol 2004; 172: 1157-1162.
35. Stuart LM, Takahashi K, Shi L, Savil J, RAB Ezekowitz. Mannose-binding lectin-deficient mice display defective apoptotic cell clearance but no autoimmune phenotype. $J$ Immunol 2005; 174: 3220-3226.

36. Munoz L, van Bavel C, Franz S, Berden J, Herrmann M, van der Vlag J. Apoptosis in the pathogenesis of systemic lupus erythematosus. Lupus 2008; 17: 371-375.

37. Sule S, Rosen A, Petri M, Akhter E, Andrade F. Abnormal production of pro-and antiinflammatory cytokines by lupus monocytes in response to apoptotic cells. PLOS ONE 2011; 6: e17495.

38. Kurosaka K, Watanabe N, Kobayashi $\mathrm{Y}$. Production of proinflammatory cytokines by resident tissue macrophages after phagocytosis of apoptotic cells. Cell Immunol 2001; 211: 1-7.

39. Yamazaki T, Naqata K, Kobayashi Y. Cytokine production by M-CSF and GM-CSFinduced mouse bone marrow-derived macrophages upon coculturing with late apoptotic cells. Cell Immunol 2008; 251: 124-130.

40. Takahashi M, Kobayashi Y. Cytokine production in association with phagocytosis of apoptotic cells by immature dendritic cells. Cell Immunol 2003; 226: 105-115.

41. Gaipl US, Kuenkele S, Voll RE, Beyer TD, Kolowos W, Heyder P et al. Complement binding is an early feature of necrotic and a rather late event during apoptotic cell death. Cell Death Differ 2001; 8: 327-334.

42. Quartier P, Potter PK, Ehrenstein MR, Walport MJ, Botto M. Predominant role of IgM-dependant activation of the classical pathway in the clearance of dying cells by murine marrow-derived macrophages in vitro. Eur J Immunol 2004; 35: 252-260.

43. Parent SA, Zhang T, Chrebet G, Clemas JA, Figueroa DJ, Ky B et al. Molecular characterization of the murine SIGNR1 gene encoding a C-type lectin homologous to human DC-SIGN and DC-SIGNR. Gene 2002; 293: 33-46.

44. Choi HJ, Choi WS, Park JY, Prabagar MG, Kang KH, Jeon SJ et al. SIGN-R1, a C-type lectin, binds to Bip/GRP78 and this interaction mediates the regurgitation of T-cellindependent type 2 antigen dextran through the endoplasmic reticulum. Immunobio/ 2011; 216: 437-446.

45. McGaha TL, Chen Y, Ravishankar B, van Rooijen N, Karlsson MC. Marginal zone macrophages suppress innate and adaptive immunity to apoptotic cells in the spleen. Blood 117: 5403-5412.

46. Ato M, Nakano $\mathrm{H}$, Kakiuchi T, Kaye PM. Localization of marginal zone macrophages is regulated by C-C chemokine ligands 21/19. J Immunol 2004; 173: 4815-4820.

47. Cesta MF. Normal structure, function, and histology of the spleen. Toxicol Pathol 2006; 34: 455-465

48. Qin X, Gao B. The complement system in liver diseases. Cell Mol Immunol 2006; 3: 333-340.

49. Dini L, Pagliara P, Carla EC. Phagocytosis of apoptotic cells by liver: a morphological study. Microsc Res Tech 2002; 57: 530-540.

50. Helmy KY, Katschke KJ Jr., Gorgani NN, Elliott JM, Diehl L et al. CRlg: a macrophage complement receptor required for phagocytosis of circulating pathogens. Cell 2006; 124: 915-927.

51. Huynh ML, Fadok VA, Henson PM. Phosphatidyl-dependant ingestion of apoptotic cells promotes TGF- $\beta 1$ secretion and the resolution of inflammation. J Clin Invest 2002; 109: $41-50$

52. Voll RE, Herrmann M, Roth EA, Stach C, Kalden JR, Girkontaite I. Immunosuppressive effects of apoptotic cells. Nature 1997; 390: 350-351

53. Fukuyama H, Nimmerjahn F, Ravetch JV. The inhibitory Fcgamma receptor modulates autoimmunity by limiting the accumulation of immunoglobulin $\mathrm{G}+$ anti-DNA plasma cells. Nat Immunol 2005; 6: 99-106.

\section{Supplementary Information accompanies the paper on Cell Death and Differentiation website (http://www.nature.com/cdd)}

